\title{
A study of soil seed banks across one complete chronosequence of secondary succession in a karst landscape
}

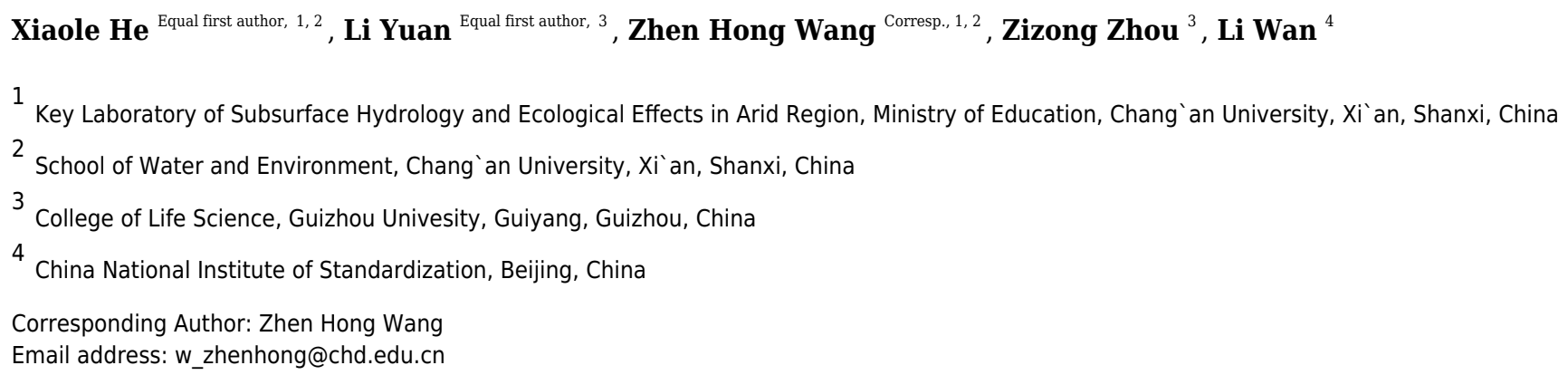

Anthropogenic disturbance and peculiar geochemistry have resulted in rocky desertification in many karst regions of the world. Seed banks are crucial to vegetation regeneration in degraded karst ecosystems characterized by a discontinuous distribution of soil and seasonal drought stress. However, the dynamics of seed banks across one complete series of secondary succession and the underlying mechanisms remain unclear. We selected eight typical stages during secondary succession, conducted aboveground vegetation survey and collected 960 soil samples in the Guiyang karst landscape of China. Seed density, species richness and plant life forms in seed banks were determined via the germination method. The results indicated that the seed density in seed banks before and after field seed germination was significantly different among most succession stages. Community succession had impacts on the seed density of seed banks before and after field seed germination. Seed density ranged from 1042 seedlings. $\mathrm{m}^{-2}$ in evergreen broadleaf forests to 3755 seedlings. $\mathrm{m}^{-2}$ in the herb community, which was a relatively high density. The seed density and similar species composition between the seed banks and vegetation declined with succession from early to later stages. Species richness in seed banks was highest in middle succession stages and increased with increasing species richness of aboveground vegetation. The species richness of the five life forms in the seed banks showed different variations across these succession stages. The conservation of diverse aboveground vegetation can maintain the diversity of seed banks for restoration. 
1 A study of soil seed banks across one complete chronosequence of secondary succession in a karst landscape

2

3 Xiaole $\mathrm{He}^{1,2}$, Li Yuan ${ }^{3}$, Zhenhong Wang ${ }^{1,2^{*}}$, Zizong Zhou ${ }^{3}$, Li Wan ${ }^{4}$

$4 \quad{ }^{1}$ Key Laboratory of Subsurface Hydrology and Ecological Effects in Arid Region, Ministry of Education, Chang an

5 University, Xi`an, China

$6 \quad{ }^{2}$ School of Water and Environment, Chang an University, 710054, Xi`an, China

$7 \quad{ }^{3}$ College of Life Science, Guizhou University, 550024, Guiyang, China

$8 \quad{ }^{4}$ China National Institute of Standardization, 100191, Beijing, China

9

10 *Corresponding author: Zhenhong Wang

11 Key Laboratory of Subsurface Hydrology and Ecological Effects in Arid Region, Ministry of Education, Chang an

12 University, Xi`an, China; School of Water and Environment, Chang an University, 710054, Xi'an, China

13 E-mail address: w_zhenhong@chd.edu.cn

14 Xiaole He and Li Yuan contributed equally to the work.

\section{Abstract}

Anthropogenic disturbance and peculiar geochemistry have resulted in rocky desertification in many karst regions of the world. Seed banks are crucial to vegetation regeneration in degraded karst ecosystems characterized by a discontinuous distribution of soil and seasonal drought stress. However, the dynamics of seed banks across one complete series of secondary succession and the underlying mechanisms remain unclear. We selected eight typical stages during secondary succession, conducted aboveground vegetation survey and collected 960 soil samples in the Guiyang karst landscape of China. Seed density, species richness and plant life forms in seed banks were determined via the germination method. The results indicated that the seed density in seed banks before and after field seed germination was significantly different among most succession stages. Community succession had impacts on the seed density of seed banks before and after field seed germination. Seed density ranged from 1042 seedlings. $\mathrm{m}^{-2}$ in evergreen broadleaf forests to 3755 seedlings. $\mathrm{m}^{-2}$ in the herb community, which was a relatively high density. The seed density and similar species composition between the seed banks and vegetation declined with succession from early to later stages. Species richness in seed banks was highest in middle succession stages and increased with 
increasing species richness of aboveground vegetation. The species richness of the five life forms in the seed banks showed different variations across these succession stages. The conservation of diverse aboveground vegetation can maintain the diversity of seed banks for restoration.

Key words: karst, soil seed bank, community succession, plant diversity, ecosystem functions

\section{Introduction}

The study of seed banks in global karst regions can predict the future of degraded ecosystem restoration, considering that aboveground vegetation is often established from the germination and growth of seeds in soil seed banks (Shen et al., 2007; Plue et al., 2017). Moreover, the data from the study on seed banks can be applied to quantify the relationships between species diversity in seed banks and aboveground vegetation. Although the compositional vegetation-seed bank dissimilarity identified in many studies indicates that a sizeable share of seed bank diversity is not represented aboveground, the seed banks responsible for the assembly of aboveground vegetation remain an important topic in ecology (Thompson and Grime, 1979; Walck et al., 2005). Seed banks are often classified into two (transient and persistent) or three (transient, short-term and long-term persistent) categories based on their annual dynamics and dormancy, according to the comparison of autumn and spring seed occurrence (Bekker et al., 1998; Funes et al., 2003; Walck et al., 2005). According to the categories of seed banks, ecologists have conducted many studies on the similarity between seed banks and aboveground vegetation and the effects of different types of disturbance and management practices on seed banks (Bakker et al., 2005; Pakeman and Small, 2005; Li et al., 2005; Ma et al., 2011; Ma et al., 2013). In recent years, qualitative and quantitative studies of seed banks have included more detailed classifications, germination patterns, spatiotemporal patterns of seed banks and mechanisms underlying the persistence of seed banks (Walck et al., 2005; Yan et al., 2010; Joe et al., 2016).

The elucidation of the dynamics of seed banks with plant community succession can provide knowledge for the restoration of degraded ecosystems, which is an important research hotpot (O'Donnell et al., 2016; Tamura et al., 2016). Thompson (2000) formulated the dominant paradigm of "declining seed numbers and diversity and decreasing similarity between seed bank and vegetation as succession proceeds.” A review based on 108 articles published between 1945 and 2006 indicates that the standing vegetation and its associated seed bank are least similar in forests, intermediately similar in wetlands and most similar in grasslands among the three studied ecosystems (Hopfensperger, 2007). This review supports the dominant paradigm because grasslands are generally considered 
57

early succession stages, whereas forest are considered to represent later succession stages in humid regions $(\mathrm{Wu}$, 1995). Recently, ecologists have finished many studies on the dynamics of seed banks, almost all of the results of which conform to the dominant paradigm with only a few exceptions (Marcante et al., 2009; Ma et al., 2011; Martinez-Duro et al., 2012; O'Donnell et al., 2016). In karst regions, previous work has primarily focused on the seed survival ratio, vegetation regeneration, seasonal variation, and the correlation of seed banks with the competitive dominance of plants for the evaluation of the recovery potential of vegetation in grasslands or degraded karst forests (Liu et al., 2001; Kalamees and Zobel, 2002; Liu et al., 2006; Shen et al., 2007; Lu et al., 2007). There is still a lack of a relatively systematic studies on the dynamics of seed banks at different depths with plant community succession in global karst regions (Kalamees and Zobel, 2002; Shen et al. 2007; Hopfensperger, 2007). The study of seed banks along a complete chronosequence of succession can reveal whether the patterns of seed banks in karst landscapes conform to the dominant paradigm widely accepted by ecologists. It can also clarify the variations in seed banks at different depths.

Karst landscapes develop from the dissolution of soluble rocks, such as limestone, dolomite and gypsum, and are often associated with intense anthropogenic activities such as extensive farming and animal grazing (Ford and Williams, 2013). Consequently, corrosion and erosion cause high proportions of bare rock and shallow, discontinuous soils (Bai, 2010). These bare rocks are very smooth due to long-term corrosion, and vegetation is often distributed in habitats with shallow, discontinuous soils (Ford and Williams, 2013). The karst landscapes in China, mainly centered in Guizhou Province, represent the largest continuous karst region in the world (Sweeting, 1993). In the region, the areas of carbonate rock outcrops cover 150 thousand square kilometers, and this stressful environment limits normal plant growth (Ford and Williams, 2013; Dai et al., 2017). It is very difficult to restore forest vegetation in these karst landscapes, and forest restoration is often dependent on soil seed banks (Dai et al., 2017). The understanding seed banks at different depths in karst landscapes not only fills a gap in the information on the horizontal and vertical variation of seed banks with plant community succession in these global fragile ecosystems but also provides knowledge for the restoration of degraded karst ecosystems. In addition, numerous studies have indicated that the loss of plant species in vegetation greatly impairs ecosystem functions and results in ecosystem instability (Loreau et al. 2001; Davis et al., 2005; Jaganathan et al., 2015). Diverse vegetation can play a great role in the maintenance of habitat sustainability, stability, and resistance to disturbance (Tilman et al., 1996; Hooper et al., 2005). Through the study of seed banks and the corresponding aboveground vegetation, the 
85

relationships between plant diversity in aboveground vegetation and in its associated seed banks can be revealed. Based on these relationships, ecologists can indirectly evaluate potential ecosystem functions, sustainability and stability at the studied sites (Wu, 1995; Joët et al., 2016).

Many ecologists have indicated that when the seeds of a plant species miss the germination season with suitable conditions, the seeds lose viability, and only transient seed banks of that plant species then remain (Thompson and Grime, 1979; Bekker et al., 1998; Funes et al., 2003; Walck et al., 2005). Conversely, if the seeds of the plant species retain viability, the plant species will exhibit persistent seed banks. In practice, plant species that appear only before field seed germination and not after field seed germination are considered to exhibit transient seed banks, while plant species that are present both before and after field seed germination exhibit persistent seed banks (Walck et al., 2005; Esmailzadeh et al., 2011; Martinez-Duro et al., 2012). However, it is still difficult to precisely differentiate plant species with transient and persistent seed banks (Walck et al., 2005; Ma et al., 2010). In this study, our focus is not to clearly differentiate plant species with transient and persistent seed banks but to elucidate the dynamics of seed banks along a series of succession stages both before and after field seed germination.

We put forth the following hypotheses: (I) the dynamics of seed banks along one chronosequence of secondary succession in a karst landscape conform to the dominant paradigm of "declining seed numbers and diversity and decreasing similarity between seed bank and vegetation as succession proceeds.", although the chronosequence is distributed in a karst landscape with unique hydrological and geological conditions; and (II) when high plant diversity is observed in aboveground vegetation along the chronosequence of secondary succession, there will also be high plant diversity in the seed banks corresponding to the aboveground vegetation due to the effects of the aboveground vegetation seed sources. To test these two assumptions, we selected a complete chronosequence of secondary succession in central Guizhou Province and investigated the aboveground vegetation. Then, soil samples were collected before and after field seed germination to test seed density and species richness in seed banks via germination methods. The objective of the study was to reveal the dynamics of seed banks along a plant community succession series in a karst region and then to clarify the relationships between plant diversity in seed banks and aboveground vegetation. We primarily answer the following questions: (1) How do seed density and species richness in seed banks and the similarity between seed banks and aboveground vegetation change from early to later succession stages? (2) What are the correlations between species richness in aboveground vegetation and its associated seed banks with community succession? 


\section{Materials and methods}

\section{Study area}

115 We sampled vegetation and seed banks in secondary succession stages of evergreen broadleaf forests within 116 Guiyang $\left(26^{\circ} 11^{\prime}-26^{\circ} 55^{\prime} \mathrm{N}, 106^{\circ} 07^{\prime} \sim 106^{\circ} 17^{\prime} \mathrm{E}\right)$ in central Guizhou Province in China (All field work was approved 117 by Administration Bureau of Two Lakes and One Reservoir in Guiyang City). Guiyang is characterized by a mid118 subtropical humid monsoon climate. The average annual rainfall is between 1148.3 and $1336.1 \mathrm{~mm}$. The average annual temperatures range from 13 to $15^{\circ} \mathrm{C}$. The different stages of secondary succession include primitive evergreen broadleaf forest (PEBF), secondary evergreen broadleaf forest (SEBF), thorn-vine shrub forest (TVSF),

121 shrub forest (SF), shrub-grass community II (SGC-II), shrub-grass community I (SGC-I), grass community-II (GCI), and grass community-I (GC-I) (Huang et al., 1988; Zhou, 1992) (Fig. 1). These eight stages of secondary succession are among the most typical types in the karst landscape of China. PEBF is a primitive type of forest that is not significantly influenced by anthropogenic disturbance. SEBF is a secondary type recovered after the intermediate cutting of PEBF. In TVSF, vines and plants with thorns are relatively more abundant than in SF, and most of the plants in the two forest types are short. SGC-I and GC-I are more influenced by grazing than SGC-II and GC-II. Therefore, in SGC-I and GC-I, plant height is relatively short. In all these stages, the soil type consists of calcareous soil, and the bare bedrock ratio is $30-70 \%$.

\section{Vegetation sampling}

We selected four representative plots of $10 \mathrm{~m} \times 10 \mathrm{~m}$ in size in PEBF and SEBF. Each individual plant in the plots was carefully identified and recorded (Huang et al., 1988; Zhou, 1992). The height and canopy coverage of these individual plants and their diameter at breast height were measured. In each plot, three subplots with a $1 \mathrm{~m} \times 1$ $\mathrm{m}$ size were set up along a diagonal plot line. All individuals of each herb species in the subplots were also recorded, and their height and base diameter were measured. In TVSF, SF, SGC-I, SGC-II, GC-I and GC-II, the size of the plots that were set up was $5 \mathrm{~m} \times 5 \mathrm{~m}$, and the number of plots was four. Similarly, we recorded the taxa of all individuals of woody plants in these plots and measured their height, canopy coverage and base diameter. Then, three $1 \mathrm{~m} \times 1 \mathrm{~m}$ subplots were set up along a diagonal line of the $5 \mathrm{~m} \times 5 \mathrm{~m}$ plot to survey the vegetation parameters of herb plants with the same method in the PEBF and SEBF.

\section{Soil sampling and experimentation}


Twenty soil sampling sites were stochastically selected in each stage, including PEBF, SEBF, TVSF, SF, SGC-

141

142

143

144

145

146

147

148

149

150

151

152

153

154

155

156

157

158

159

160

161

162

163

164

165

166

167

II, SGC-I, GC-II and GC-II sites. These sites were all distributed in the area where vegetation was surveyed. Spring comes relatively earlier in Guiyang, which is characterized by a mid-subtropical humid monsoon climate, than it does in a temperate climate. Thus, soil samples were collected at the end of February and May to separately describe the seed banks before field seed germination and the seed banks after field seed germination but before the dispersal of the current-season seeds. Soil samples were collected with a small shovel in an area of $10 \mathrm{~cm} \times 10 \mathrm{~cm}$ at each soil sampling site and were divided into three depths: $0-5 \mathrm{~cm}, 5-10 \mathrm{~cm}$ and $10-15 \mathrm{~cm}$. The volume of each soil sample was $500 \mathrm{~cm}^{3}$. After soil sampling, small stones in the soil samples were picked out, and the large bulk soil sample was broken up by hand. All soil samples were initially dried in laboratory and then kept at $4.5^{\circ} \mathrm{C}$ for a month to break seed dormancy. The number of soil samples in each stage of secondary succession was 120 (two collections). The total number of soil samples in all eight stages of secondary succession was 960 .

Germination trays $(20 \mathrm{~cm} \times 20 \mathrm{~cm}$ size $)$ were filled with fine sands that had been sterilized at high temperature to a depth of approximately $2-3 \mathrm{~cm}$. Then, the soil samples were placed in the germination trays. The germination trays were cultivated in a large greenhouse at the farm of Guizhou University. To ensure that the seeds in the soil samples not contaminated, we constructed a small greenhouse from vinyl inside of the large greenhouse, and the germination experiment was conducted in the small greenhouse. The temperature in the small greenhouse was maintained at 20 to $30^{\circ} \mathrm{C}$. We identified each of the germinated seedlings and counted their number at 10-day intervals. The identified seedlings were directly removed. Unidentified taxa were transplanted into individual pots and allowed to grow until identification was possible. As no seedlings were observed in the germination experiments, the soil samples in the germination trays were thoroughly mixed and dried in a small greenhouse. Then, we continued to conduct a germination experiment until all seeds in the soil samples had germinated. The whole germination experiment lasted from April to February of the following year.

\section{Data analysis}

The aboveground vegetation data were used to quantify the important values (IV) of plant species in each successional stage (Supplemental Information I). IV represented the dominance of species in aboveground plant community.

The data from the germination experiment were considered at the scale of $10 \mathrm{~cm} \times 10 \mathrm{~cm}$ plots. We obtained data on seedlings and species richness among the seedlings at each stage and calculated their average, maximum and

Peer) reviewing PDF | (2020:05:48689:2:0:NEW 25 Sep 2020) 
minimum values. Furthermore, the germination experiment data were processed to obtain the density of seeds per square meter. The normality of the data was tested with P-P figures. The data were analyzed using one-way ANOVA and LSD tests in IBM SPSS Statistics 19 to distinguish the differences in seed density between different stages. The number of seeds present for different plant life forms in the seed banks before and after seed germination was also identified.

We further gave the list of all plant species in both the $10 \mathrm{~m} \times 10 \mathrm{~m}$ or $5 \mathrm{~m} \times 5 \mathrm{~m}$ plots of woody plants and 1 $\mathrm{m} \times 1 \mathrm{~m}$ plots of herbs in each stage (Supplementary Information I) and the lists of all plant species germinating from 20 soil samples for each layer of soil in the range of the stage (Supplementary Information II). Then, the common species of the two lists of plant species in the aboveground vegetation and seed bank were identified in each stage. Equation (1) was used to calculate the similarity of the plant species between the seed banks and the aboveground vegetation for each stage.

$$
C_{j} \frac{j}{a+b-j} \times 100 \%
$$

where $\mathrm{C}_{\mathrm{j}}$ is the Jaccard index; $a$ and $b$ represent the number of species in the seed banks and aboveground vegetation, respectively; and $j$ is the number of common species occurring in the seed banks and aboveground vegetation.

Then, plant species were classified by their life forms into ephemeral herbs, perennial herbs, vines, shrubs and trees. Regression models were established with SPSS to fit the relationships between the richness of plant species in the seed banks and succession stages (qualitative regression), and between the richness of plant species and respective plant life forms in the seed banks and richness of plant species in aboveground vegetation in these eight succession stages (quantitative regression). The homogeneity of variance was determined by Levene`s tests for large samples. The correlation coefficients between regression residuals and predicted variables or independent variables were used to determine the homoscedasticity of the data for small samples because the coefficients can indirectly represent the homogeneity of variance for dependent variables (Zhu, 2017). All analyses and tests are included in the raw data files that have been uploaded to the system.

\section{Results}

\section{Dynamics of seed banks along the succession series}

\section{Seed density of recorded species}

We identified 89 species in the seed banks both before and after field seed germination in all succession stages (Table 1; Supplemental Information II). These plant species included 71 herb species, 3 vine species, 10 shrub 
196

197

198

199

200

201

202

203

204

205

206

207

208

209

210

211

212

214

215

216

217

218

219

220

\section{1}

222

223

species and 5 tree species. The number of species occurring in seed banks before and after field seed germination ranged from 20 to 38 and from 23-31, respectively (Table 1). The number of common species ranged from 11 to 19. There were many viable seeds in each succession stage. For the species with the most seeds, 33-106 seedlings were recorded in these stages, but only 1-3 seedlings of the species with the fewest seeds were observed. The species with the most seeds were all herb plants, such as Digitaria sanguinalis, Arthraxon hispidus, Arthraxon lanceolatus, Setaria viridis, Centella asiatica, and Oxalis corniculata. The greatest seed number in the seed banks was observed for herb plants, which accounted for $62.9 \%$ of the total seed number. Herb plants occurred in nearly every succession stage. However, woody plants mainly occurred in the seed banks of TVSF, SF, SEBF and PEBF. The highest total species richness occurred in the seed banks from intermediate stages within the series of community succession.

\section{Total seed density in different stages}

There were abundant seeds in the seed banks before and after field seed germination in the different stages of secondary succession (Table 2). Among these stages, CG-II, which was relatively less influenced by grazing than GC-I, exhibited the most seedlings: 3755 and $1650 . \mathrm{m}^{-2}$ (total in three soil depths). SEBF and PEBF presented the fewest seedlings. The seed density in the early succession stages in which herbs dominated aboveground was greater than that in later stages. The seed density in seed banks before field seed germination was higher than after field seed germination in all stages of secondary succession. However, the differences in seed density in the seed banks before and after field seed germination were small in the later stages. With increasing soil depth, the number of recorded seedlings decreased. In addition, there was great variation in seed density among different sites in the same successional stage.

The seed density in the seed banks before and after field seed germination differed significantly among most of the successional stages (Supplemental Information III). No difference was generally observed between neighboring succession stages. There were relatively less significant differences in the seed density of seed banks after field seed germination between succession stages than before field seed germination. However, the seed density of the seed banks both before and after field seed germination showed more significant differences between successional stages.

\section{Seed density of different life forms}

The seed density of ephemeral and perennial herbs in the seed banks in different succession stages was also greater before field seed germination than after field seed germination (Table 3). The seed density of these two life 
224

225

226

227

228

229

230

231

232

233

234

235

236

237

238

239

240

241

242

243

244

245

246

247

248

249

250

251

forms showed a decreasing trend with community succession from early to later stages. However, trees showed an increasing trend in seed density. Vines presented relatively high seed density in middle succession stages. The seed density of ephemeral and perennial herbs was far greater than that of vines, shrubs and trees. There was a grazing disturbance in GC-I compared to GC-II, and the seed density of ephemeral and perennial herbs was accordingly greater in GC-I than in GC-II.

\section{Similarity of plant species between seed banks and aboveground vegetation}

Before and after field seed germination, the similarity of plant species among the seed banks from the three soil depths and the aboveground vegetation declined with community succession from early to later stages (Table 4). Early succession stages GC-I and GC-II exhibited much higher similarity than the later stages. Comparatively, the species composition in the seed banks before field seed germination showed higher similarity than that after field seed germination except in SGC-II and PEBF. However, only few plant species, e.g., Digitaria sanguinalis, Arthraxon hispidus, Arthraxon lanceolatus, and Zanthoxylum planispinum Sieb.et Zucc., showed similar dominances in both seed banks and aboveground vegetation based on the data of vegetation and seed banks for concrete plant species (Supplementary Information I and II). The similarity of the plant species between the seed banks from the different soil depths and aboveground vegetation also decreased with community succession from early to later stages. The similarity coefficients $\left(C_{j}\right)$ among the different soil depths were mostly lower than those over the depth of $0-15 \mathrm{~cm}$. The $C_{j}$ values for the surface soil layer were mostly greater than those for the deep soil layer.

\section{Relationships between species richness in seed banks and aboveground vegetation}

\section{Species richness in seed banks across different succession stages}

Before field seed germination, species richness in the seed banks at soil depths of 5-10 cm and 10-15 cm showed a weak, nonsignificant increase $(P>0.05)$ from early to later succession stages under decreasing similarity of the species composition between the seed banks and the aboveground vegetation, but at the depth of $0-5 \mathrm{~cm}$, there was a slight decrease $(P>0.05)$ (Fig. 2A-C ). However, after field seed germination, species richness in the seed banks at the three depths showed a statistically significant increase $(P<0.05)$ (Fig. 2D-F). Species richness in the seed banks both before and after field seed germination decreased with increasing soil depth based on the trend line. Comparatively, species richness in the seed banks at the three depths before field seed germination was higher than that after field seed germination. There was great variation in species richness in the seed banks of each succession 
252

253

stage among sampling plots according to the highly variable standard deviation (error line) of species richness in the seed banks.

\section{Species richness of different life forms in seed banks across different succession stages}

Before field seed germination, the species richness of ephemeral and perennial herbs in seed banks at the three soil depths first increased and then decreased with community succession from early to later stages (Fig. 3A). However, the species richness of shrubs, vines and trees differed from that of ephemeral and perennial herbs, which changed in a linearly increasing form across these stages. After field seed germination, there was no great change in the species richness of ephemeral herbs in the seed banks with community succession (Fig. 3B). For perennial herbs, two peaks of species richness occurred in GC-I and SGC-II; species richness was similar among the other stages. The species richness of shrubs and trees increased across these stages, analogous to what was observed in the seed banks before field seed germination. For vines, there was a humped distribution of species richness across these stages. The fitted models of the species richness of different life forms at different stages were statistically significant except for the species richness of vines (Table 5). These fitted models showed humped, positive or negative linear shapes.

\section{Relationship between species richness in seed banks and aboveground vegetation}

Both before and after field seed germination, an increase in species richness in the seed banks with increasing species richness of aboveground vegetation was a dominant pattern (irrespective of the succession stage) (Fig. 4). Species richness in aboveground vegetation could not explain the variation in species richness in the seed banks before field seed germination (Fig. 4A-C). However, species richness in aboveground vegetation could explain 16.9$54.4 \%$ of the variation in species richness in the seed banks after field seed germination (Fig. 4D-F); the explanatory power of the species richness of aboveground vegetation decreased with soil depth. Overall, the variation in species richness in the seed banks before field seed germination was not dependent on the species richness of aboveground vegetation. Species richness in the seed banks after field seed germination was partially dependent on the species richness of aboveground vegetation.

\section{Relationships between the species richness of different life forms in seed banks and aboveground vegetation}

The species richness of ephemeral and perennial herbs in the seed banks before field seed germination slowly decreased and increased, respectively, with increasing species richness of aboveground vegetation (Fig. 5A and B). The species richness of ephemeral and perennial herbs in the seed banks after field seed germination showed 
280 irregular variation with increasing species richness (Fig. 5F and G). In the seed banks before and after field seed

281 germination, vine, shrub and tree species showed an identical pattern of species richness; i.e., species richness 282 continually increased with increasing species richness of aboveground vegetation (Fig. 5C-E and Fig. 5H-J).

283 However, there was often high species richness of vines, shrubs or trees in some soil samples from a given stage but low richness or no representation of that life form in other soil samples from that stage. Consequently, the standard deviation was even greater than the mean (Fig. 5C-E and Fig. 5H-J).

\section{Discussion}

287 We found that total seed density and the seed density of ephemeral and perennial herbs in the seed banks both before 288 and after field seed germination and the similarity between the seed banks and aboveground vegetation declined 289 from early to later stages of secondary succession in the Guiyang karst landscape. These results conform to the 290 dominant paradigm of "declining seed numbers and diversity and decreasing similarity between seed bank and 291 aboveground vegetation as succession proceeds" (Thompson, 2000). Many results obtained from recent studies also 292 support the pattern of declining seed density and similarity with plant community succession (Shen et al., 2007;

293 Kwiatkowska-Falińska et al., 2011; Egawa and Tsuyuzaki, 2013; Kiss et al., 2017). In the complete chronosequence of secondary succession in the karst landscape, aboveground ephemeral and perennial herbs were dominant in terms of both individual density and species richness at early stages. A large number of seeds from these herbs were identified in the germination experiment. This resulted in a high seed density in seed banks and high species composition similarity between the seed banks and aboveground vegetation. However, shrubs and trees began to become dominant at the later stages of succession, and the seeds of herbs decreased. Conversely, the seeds of woody plants increased, but the number of seeds from woody plants was far lower than that from herbs. Therefore, the total density of the seed banks continually decreased with plant community succession. There were also numerous seeds of herbaceous plant species in soil but relatively few aboveground herbaceous species in later stages under dominant shrubs or trees. The herbaceous plant species in the seed banks were primarily the same species that occurred in early herbaceous-dominant stages, such as GC-I and GC-II. As a consequence, the similarity of the species composition between the seed banks and aboveground vegetation also declined with plant community succession. However, our results regarding the similarity of the species composition with community succession were also different from those of a few studies in European and Chinese grasslands (Marcante et al., 2009; Ma et al., 2011;

307 Martinez-Duro et al., 2012). In these studies, the species composition similarity between seed banks and 
308 aboveground vegetation was found to decrease with community succession because some distinct species occurred

309 in the aboveground vegetation that decreased the species composition similarity from early to later stages. Moreover,

310 the similarity $(<20 \%)$ between the seed banks and karst forests (SEBF and PEBF) in this study was far lower than

311 that found in temperate secondary forests in northeastern China (Yan et al., 2010), wet dun slacks in the Netherlands

312 (Bakker et al., 2005), and a subalpine pasture in the Alps of Europe (Marcante et al., 2009). Ecosystem restoration

313 data indicate that the later stage of succession often represents the type of forest to which society wants land restored

314 via hard work. Therefore, our finding of low species similarity between seed banks and aboveground vegetation in

315 later stages of succession implies that seed introduction by dispersal to these eight typical stages of secondary

316 succession is a natural regeneration strategy that is worthy of an attention for restoring degraded karst landscapes to

317 forests.

318 It was found that the total seed density in the seed banks both before and after field seed germination in 319 different stages in the Guiyang karst landscape was significantly greater than that in plant communities in which there in no bare rock in other regions. For example, a density of $84-562$ seedlings $\mathrm{m}^{-2}$ was observed in soil seed banks at a depth of 0-10 cm in different stages of secondary succession in south subtropical forests (Huang et al., 1996), 400-1400 seedlings $\mathrm{m}^{-2}$ in forest floor litter and soils at a depth of 0-5 $\mathrm{cm}$ in temperate forests in northeast China (Yan et al., 2010), 642-985 seedlings in soil seed banks of a cool-temperate, damp old-growth forest in Japan (Tamura, 2016), and fewer than 400 seedlings $\mathrm{m}^{-2}$ in soil seed banks at a depth of $0-12 \mathrm{~cm}$ in three alpine meadows on the Tibetan Plateau (Ma, 2010). The densities observed along a well-preserved chronosequence in the Alps of Austria ranged from 273 seedlings $\mathrm{m}^{-2}$ in soil seed banks at a depth of $0-10 \mathrm{~cm}$ in the pioneer stage to 820 seedlings $\mathrm{m}^{-2}$ in the early stage and 3527 and 3674 seedlings $\mathrm{m}^{-2}$ in later stages; the seed density of the seed banks in these stages was lower than that in the stages of secondary succession in that study (Marcante et al., 2009). However, the total seed density in the seed banks of both a secondary forest and Distylium chinensis communities in areas consisting of 50-70\% bare rocks in a similar-latitude karst region of Guizhou Province was similar to the total seed density found in this study (Liu et al., 2006; Liu, 2001; Lu et al., 2007). In another tropical karst region of China, a seed density of 3,900-14,900 seedlings. $\mathrm{m}^{-2}$ was observed in soil seed banks in tropical grass, shrub and forest communities, which was significantly higher than those found in the Guiyang karst landscape in our study and in other nonkarst regions (Shen et al., 2007; Hopfensperger, 2007); these tropical karst communities were characterized 
336 environment, and the seed density in seed rains is often low (Liu et al., 2001; Shen et al., 2007). However, the data

obtained from the karst landscape indicate a higher density of the seeds in seed banks than is found in other regions. Based on our field observations, when seeds fall on the surface of smooth bare rocks during seed rains in karst landscapes, these seeds are easily carried by wind or rainwater to the areas between the bare rocks (Wang et al., 2014). Through above comparisons, we therefore infer that there may be a concentration effect of bare rocks on seed rains that results in a high seed density in seed banks during a succession series in a karst landscape. However, this effect needs to be verified by the results obtained under a different experimental design.

The total species richness in the seed banks before and after field seed germination from early to later succession stages was high in intermediate stages but showed relatively small differences among these stages. However, the species richness in the seed banks before and after field seed germination for respective soil layers increased from early to later succession stages. This pattern is different from the decreasing diversity indicated by the dominant paradigm (Thompson 2000), which is analogous to findings in central European grasslands (Kiss et al., 2017). In intermediate succession stage, there were few shrubs and trees, but herbaceous plants were still abundant, which caused some shade, but the habitats still received abundant sunlight. These conditions were beneficial to the maintenance of seed viability for different plant species (Jaganathan and Dalrymple, 2015). Conversely, early and later stages might be slightly drier and wetter, respectively, making them unfavorable to seed viability for some plant species. Therefore, the intermediate stages exhibited the highest species richness in seed banks. The species richness of the different plant life forms in seed banks both before and after field seed germination showed a humped, positive or negative linear shape across these stages. The species richness of ephemeral and perennial herbs across all stages was approximately 2-10 times greater than that of shrubs, vines and trees. These are similar to the levels of species richness reported in second-growth stands, old-growth stands and logged stands in tropical wet forests (Dupuy and Chazdon, 1998) and in grazed and ungrazed eucalypt woodlands (Grant and Macgregor, 2001). In steppe deserts, ephemeral herbs have been found to account for a much higher percentage ( $>90 \%)$ of the species richness in seed banks than perennial herbs and shrubs $(<5 \%)$, and the ratio of herbs was considerably higher than that indicated by our results (De et al., 2008). The life-form pattern found here also disagrees with that reported in the Santa Genebra Municipal Reserve of Brasil, where trees account for $47.8 \%$ of the total species richness, which is much greater than the contributions of herbs and shrubs (6.5\% and 16.5\%, respectively) (Grombone-Guaratini and Rodrigues, 2002). 
Although there are many reports of species richness in seed banks, the relationship of the species richness in seed banks with the associated aboveground vegetation under decreasing similarity of the species composition across an individual chronosequence is seldom analyzed (Hopfensperger, 2007). We conducted an analysis using the data for the species in the karst landscape. The species richness in seed banks after field seed germination significantly increased with increasing species richness of aboveground vegetation under decreasing similarity of the species composition, but the species richness in seed banks before field seed germination was maintained at an almost invariable level. The species richness of shrubs, trees and vines in seed banks also increased with increasing species richness of aboveground vegetation, but the species richness of ephemeral and perennial herbs showed almost no change. These results partially validate hypothesis II. Although we did not intend to clearly differentiate plant species with transient and persistent seed banks, the data on the seed banks before and after field seed germination to some degree represent plant species with transient and persistent seed banks, respectively (Funes et al., 2003; Walck et al., 2005). Therefore, the above results can indicate that the change in species richness in transient and persistent seed banks differs with increasing species diversity of aboveground vegetation, but the changes in the species richness of shrubs, trees and vines in both transient and persistent seed banks are identical. Plant diversity in aboveground vegetation can play a great role in ecosystem services (Tilman et al., 1996 Hooper et al., 2005; Davis et al., 2005; Jaganathan et al., 2015; Joët et al., 2016). These monotonically increasing relationships between the species richness of aboveground vegetation and seed banks mean that high plant richness in seed banks has a great potential to provide ecosystem services to humans in the long run (Loreau and Hector, 2001).

\section{Conclusions}

Decreasing seed density and species composition similarity with both community succession and decreasing soil depths is a dominant pattern in karst landscapes. Community succession has a significant impact on the seed density in seed banks before and after field seed germination. The seed density in the seed banks of karst plant communities is relatively high, and there is consequently good potential for the restoration of degraded ecosystems from seed banks. The total species richness in seed banks and the species richness of shrubs, vines and trees increase with increasing species richness of aboveground vegetation. The decreasing species composition similarity between 
392 outside area. High plant diversity in aboveground vegetation is beneficial to the maintenance of plant diversity in 393 seed banks.

\section{Acknowledgements}

This work was supported by grants from the Fundamental Research Funds for the Central Universities (No. 300102299303) and the National Natural Science Foundation of China (No. 40861015).

\section{References}

1. Bai XY, Zhang XB, Chen H, He YB. 2010. Using 137Cs fingerprinting technique to estimate sediment deposition and erosion rates fromYongkang depression in the karst region of Southwest China. Land Degradation \& Development 21: 474-479 DOI 10.1002/ldr.983.

2. Bakker C. de Graaf HF, Ernst WHO,van Bodegom PM. 2005. Does the seed bank contribute to the restorationof species-rich vegetation in wet dune slacks? Applied Vegetation Science 8: 39-48 DOI 10.1658/1402-2001(2005)008.

3. Bekker RM, Bakker JP, Grandin U, Kalamees R, Milberg P, Poschlod P, Thompson K, Willems JH. 1998. Seed size, shape and vertical distribution in the soil: indicators of seed longevity. Functional Ecology 12: 834-842 DOI.10.1046/j.1365-2435.1998.00252.x.

4. Dai Q, Peng X, Zhao L, Shao H, Yang Z. 2017. Effects of underground pore fissures on soil erosion and sediment yield on karst slopes. Land Degradation \& Development 28: 1922-1932.

DOI.10.1002/ldr.2711.

5. Davis AS, Cardina J, Forcella F, ohnson GA, Kegode G, Lindquist JL, Luschei EC, Renner KA, Sprague CL, Williams II, MM. 2005. Environmental factors affecting seed persistence of annual weeds across the U.S. corn belt. Weed Science 53: 860-868.

6. De Y, Aotegen, Bureniya. 2008. Effects of different grazing intensities on species diversity and life form of soil seed bank in steppe desert. Arid Zone Research 25: 637-641.

7. Dupuy JM, Chazdon RL.1998. Long-term effects of forest regrowth and selective logging on the Seed bank of tropical forests in NE Costa Rical. Biotropica 30: 223-237 DOI.10.1111/j.1744- 
7429.1998.tb00057.x.

8. Egawa C, Tsuyuzaki S. 2013. The effects of litter accumulation through succession on seed bank formation for small-and large-seeded species. Journal of Vegetation Science 24:1062-1073 DOI.10.1111/jvs.12037.

9. Esmailzadeh O, Hosseini SM, Tabari M, Baskin CC, Asadi H. 2011. Persistent soil seed banks and floristic diversity in Fagusorientalis forest communities in the Hyrcanian vegetation region of Iran. Flora 206: 365-372 DOI.10.1016/j.flora.2010.04.024.

10. Ford D, Williams PD. 2013. Karst hydrogeology and geomorphology. Hoboken: John Wiley \& Sons.

11. Funes G, Basconcelo S, Díaz S, Cabido M. 2003. Seed bank dynamics in tall-tussock grasslands along an altitudinal gradient. Journal of Vegetation Science 14: 253-258 DOI.10.1658/1100-9233 (2003)014.

12. Grant C, Macgregor C. 2001. Topsoil seed banks in grazed and ungrazed eucalypt woodlands at Newholme, Armidale, New South Wales, Australia. New Zealand Journal of Botany 39: 471-481 DOI.10.1080/0028825X.

13. Grombone-Guaratini MT, Rodrigues RR. 2002. Seed Bank and Seed Rain in a Seasonal Semi-Deciduous Forest in South-Eastern Brazil. Journal of Tropical Ecology 18: 759-774

DOI.10.1017/S0266467402002493.

14. Hooper DU, Chapin III FS, Ewel JJ, Hector A, Inchausti P, Lavorel S, Lawton JH, Lodge DM, Loreau M, Naeem S, Schmid B, Setälä H, Symstad AJ, Vandermeer J, Wardle DA. 2005. Effects of biodiversity on ecosystem functioning: a consensus of current knowledge. Ecology Monographs 75: 3-35.

15. Hopfensperger KN. 2007. A review of similarity between seed bank and standing vegetation across ecosystems.Oikos 116:1438-1448 DOI.10.1111/j.0030-1299.2007.15818.x.

16. Huang WL, Tu YL, Yang, L.1988. Guizhou vegetation. Guiyang of China: Guizhou People Press.

17. Huang ZL, Kong GH, Wei P, Wang JH, Huang YJ, Zhang RC. 1996. A study on the soil seed bank at different succession stages of south subtropical forests. Journal of Tropical and Subtropical botany 4: 4249.

18. Jaganathan GK, Dalrymple SE, Liu BL. 2015. Towards an understanding of factors controlling seed bank composition and longevity in the Alpine Environment. Botany Review 81: 70-103

DOI.10.1007/s12229-014-9150-2 
19. JoeT, Ourcival JM, Capelli M, Dussert S, Morin X. 2016. Explanatory ecological factors for the persistence of desiccation-sensitive seeds in transient soil seed banks: Quercus ilex as a case study. Annals of Botany 117: 165-176 DOI.10.1093/aob/mcv139.

20. Kalamees R, Zobel M. 2002. The role of the seed bank in gap regeneration in a calcareous grassland community. Ecology 83: 1017-1025 DOI.10.2307/3071910.

21. Kiss R, Valkó O, Tóthmérész B, Török P. 2017. Seed bank research in central-European grasslandsoverview. In: Murphy J. ed. Seed banks: types, roles and research. New York: Nova Science Publishers, 1-34.

22. Kwiatkowska-Falińska AJ, Jankowska-Blaszczuk M, Wódkiewicz M. 2011. The pattern of seed banks during secondary succession on poor soils. Acta Societatis Botanicorum Boloniae 80: 269-274 DIO.10.5586/asbp.2011.040.

23. Liu JM.2001.The seed banks and the germinative characters of the Distyliumchinensis community in Guizhou, Maolan karst forest. Acta Ecologica Sinca 21: 197-203.

24. Liu JM, Chen H, He YJ, Li ZD. 2006. Study on soil seed bank in enclosured hillsides for regeneration of karst areas. Journal of Southwest Agricultural University 28: 376-380.

25. Loreau M, Hector A. 2001. Partitioning selection and complementarity in biodiversity experiments. Nature 412: 72-76 DOI.10.1038/35083573

26. Lu SH, Lu SH, Ou ZL, Xiang WS, Wang XY, Qin J. 2007. Basic characters of soil seed bank and measures of vegetation restoration in rock desertification area in southwest of Guangxi. Journal of Plant Resources and Environment 16: 6-11.

27. Ma MJ, Zhou XH, Du GZ. 2011. Soil seed bank dynamics in alpine wetland succession on the Tibetan Plateau. Plant and Soil 346:19-28 DOI.10.1007/s11104-011-0790-2.

28. Ma MJ, Zhou XH, Du GZ. 2013. Effects of disturbance intensity on seasonal dynamics of alpine meadow soil seed banks on the Tibetan Plateau. Plant and Soil 369: 283-295 DOI.10.1007/s11104-012$1560-5$

29. Ma MJ, Zhou XH, Wang G, Ma Z, Du GZ. 2010. Seasonal dynamics in alpine meadow seed banks along an altitudinal gradient on the Tibetan Plateau. Plant and Soil 336: 291-302 DOI.10.1007/s11104-010$0480-5$ 
30. Marcante S, Schwienbacher E, Erschbamer B. 2009. Genesis of a soil seed bank on a primary succession in the Central Alps (Ötztal, Austria).Flora 204: 434-444 DOI.10.1016/j.flora.2008.06.001.

31. Martinez-Duro E, Luzuriaga AL, Ferrandis P, Escudero A, Herranz JM. 2012. Does aboveground vegetation composition resemble soil seed bank during succession in specialized vegetation on gypsum soil? Ecological Research 27: 43-51 DOI.10.1007/s11284-011-0870-z.

32. O'Donnell J, Fryirs KA, Leishman MR.2016. Seed banks as a source of vegetation regeneration to support the recovery of degraded rivers: A comparison of river reaches of varying condition. Science of the Total Environment 542: 591-602 DOI.org/10.1016/j.scitotenv.2015.10.118.

33. Pakeman RJ, Small JL. 2005. The role of the seed bank, seed rain and the timing of disturbance in gap regeneration. Journal of Vegetation Science 16: 121-130 DOI.10.1111/j.1654-1103.2005.tb02345.x.

34. Plue J, De Frenne P, Acharya K, Brunet J, Chabrerie O, Decocq G, Diekmann M, Graae BJ, Heinken T, Hermy M, Kolb A, Lemke I, Liira J, Naaf T, Verheyen K, Wulf M, Cousins SAO. 2017. Where does the community start, and where does it end? Including the seed bank toreassessforest herb layer responses to the Environment. Jouranl ofVegetation Science 28: 424-435 DOI.10.1111/jvs.12493.

35. Shen YX, Liu WY, Cao M, Li YH. 2007. Seasonal variation in density and species richness of soilseedbanks in karst forests and degraded vegetation in central Yunnan, SW China. Seed Science Research 17: 99-107 DOI.10.1017/S0960258507708139.

36. Sweeting MM. 1993. Reflections on the development of karst geomorphology in Europe and a comparison with its development in China. Geomorphology 37: 127-138.

37. Tamura A. 2016.Potential of soil seed banks in the ecological restoration of overgrazed floor vegetation in a cool-temperate old-growth damp forest in eastern Japan. Journal of Forest Research 21: 4356.DOI.10.1007/s10310-015-0509-y.

38. Thompson K. 2000. The functional ecology of soil seed banks. In: Fenner M. ed. Seeds: the ecology of regeneration inplant communities. Wallingford: CABI publishing, 215-235.

39. Thompson K, Grime JP. 1979. Seasonal variation in the seed banks of herbaceous species in ten contrasting habitats. Journal of Ecology 67: 893-921 DOI.10.2307/2259220.

40. Tilman D, Wedin D, Knops J. 1996. Productivity and sustainability influenced by biodiversity in 
grassland ecosystems. Nature 379: 718-720 DOI.10.1038/379718a0.

41. Walck JL, Baskin JM, Baskin CC, Hidayati SN. 2005. Defining transient and persistent seed banks in species withpronounced seasonal dormancy and germination patterns. Seed Science Research 15: 189196 DOI.10.1079/SSR2005209.

42. Wang ZH, Yang LM, Yang CB, Zhou ZZ, Yuan L, Xu WY, Liao CG. 2011. Typical terrestrial ecosystem in Yungui Plateau in China: patterns and processes of typical forests and shrub communities. Beijing: Science Press.

43. Wu ZY. 1995. China Vegetation. Bejing: Science Press.

44. Yan Q, Zhu J, Zhang J, Yu L, Hu Z. 2010. Spatial distribution pattern of soil seed bank in canopy gaps of various sizes in temperate secondary forests, northeast China. Plant and Soil 329: 469-480 DOI. 10.1007/s11104-009-0172-1.

45. Yan QL, Zhu JJ, Zhang JP, Yu LH. Hu ZB. 2010. Spatial distribution pattern of soil seed bank in canopy g various sizes in temperate secondary forests, northeast China. Plant and Soil 329: 469-480 DOI.10.1007/s1 009-0172-1.

46. Zhu YZ.2017. A test for heteroskedasticity in regression model. Jouranl of Chongqing Technology and Bus University, 34(6): 34-37.

47. Zhou ZX. 1992. Guizhou forests. Guiyang of China: Guizhou Science and Technology Press.

$400 \quad$ Figure legends

Fig. 1 Different stages of secondary succession in the Guiyang karst landscape. A: GC-I; B: GC-II; C: SGC-I; D: SGC-II; E: TVSF; F: SF; G: SEBF; H: PEBF.

Fig. 2 Changes in species richness in seed banks across different stages of secondary succession. A, B and C are the seed banks before field seed germination at the soil depths of 0-5, 5-10 and 10-15 cm, respectively; D, E and F are the seed banks after field seed germination at the three different soil depths. Each stage of secondary succession corresponds to twenty species richness values obtained from twenty soil samples in one layer of soil $(N=160$ in each small figure). Species richness shows a normal distribution based on P-P figures. The variance in species richness at different successional stages is homogeneous. * $*$, and ** represent significance at confidence levels of $95 \%, 99 \%$ and $99.9 \%$, respectively. $\mathrm{X}$ in equations represents succession stages. The notation is the same in the table and the figures below. 
413 Fig. 3 Species richness of five plant life forms in seed banks before field seed germination (A) and after field seed 414 germination (B). The species richness represented by each pillar is the number of all species of one life form 415 recorded from 60 soil samples (total at three depths; each soil sample is collected from a $10 \mathrm{~cm} \times 10 \mathrm{~cm}$ plot) in one 416 succession stage. The species richness of all plant life forms shows a normal distribution based on P-P figures. The 417 variance of the species richness for ephemeral and perennial plants (excluding shrubs, vines and trees) in different 418 successional stages is homogeneous.

419

Fig. 4 Relationship of the species richness in seed banks with the species richness of aboveground vegetation. A, B and $\mathrm{C}$ represent species richness in soil seed banks before field seed germination at depths of 0-5, 5-10 and 10-15 $\mathrm{cm}$, respectively; D, E and F represent the soil seed banks after field seed germination at the three depths. The value of each dot in the figures is the mean species richness determined from twenty soil samples collected in each succession stage. The species richness on the $\mathrm{x}$-axis corresponding to each dot in the figures is the mean species richness surveyed from four plots (for woody plants) and 12 subplots (for herb plants) in each succession stage. Note: the species richness of the aboveground vegetation and seed banks is highest in middle succession stages. Species richness shows a normal distribution based on P-P figures. The variance of species richness associated with different levels of the species richness of aboveground vegetation is homogeneous based on statistical tests.

Fig. 5 Relationship of the species richness of different life forms in seed banks with the species richness of aboveground vegetation. A, B, C, D and E represent the ephemeral herbs, perennial herbs, vines, shrubs and trees, respectively, included in seed banks before field seed germination; F, G, H, I, and J represent the ephemeral herbs, perennial herbs, vines, shrubs and trees, respectively, included in seed banks after field seed germination. The values of each dot in the figures are the mean species richness tested from sixty soil samples (total at three soil depths) in each stage of secondary succession. Species richness on the X-axis is the same as in Fig. 4. The species richness of all plant life forms shows a normal distribution based on P-P figures. The variance of the species richness at different levels of the species richness of aboveground vegetation is homogeneous based on statistical tests. 
Figure 1

Different stages of secondary succession in the Guiyang karst landscape

A: GC-I; B: GC-II; C: SGC-I; D: SGC-II; E: TVSF; F: SF; G: SEBF; H: PEBF 


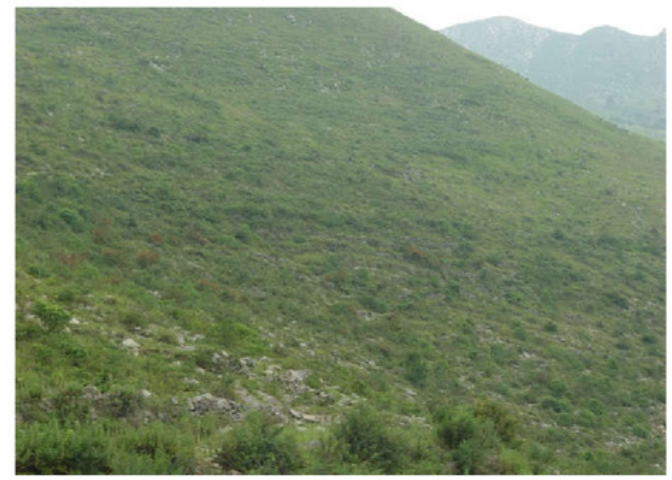

A

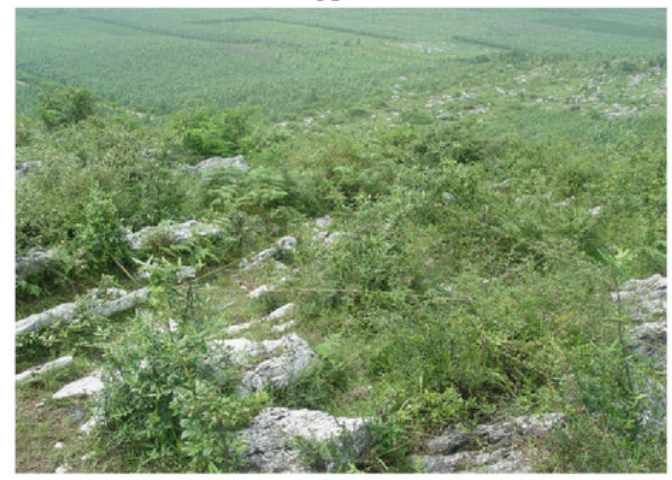

C

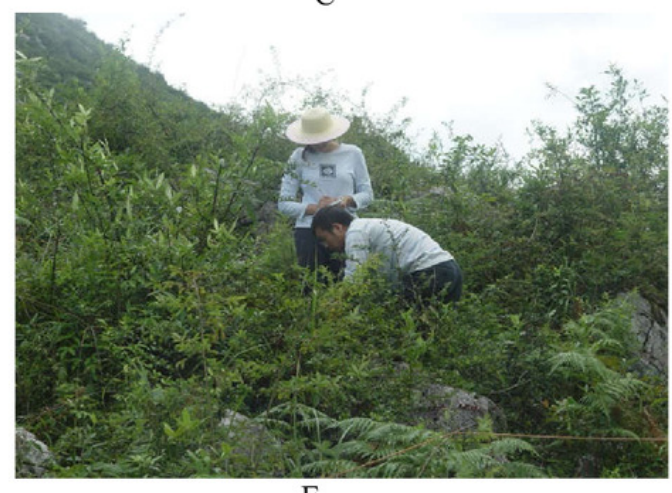

E

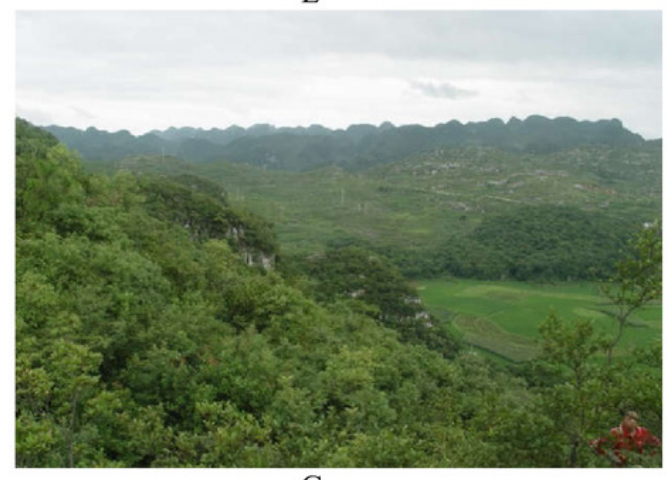

G
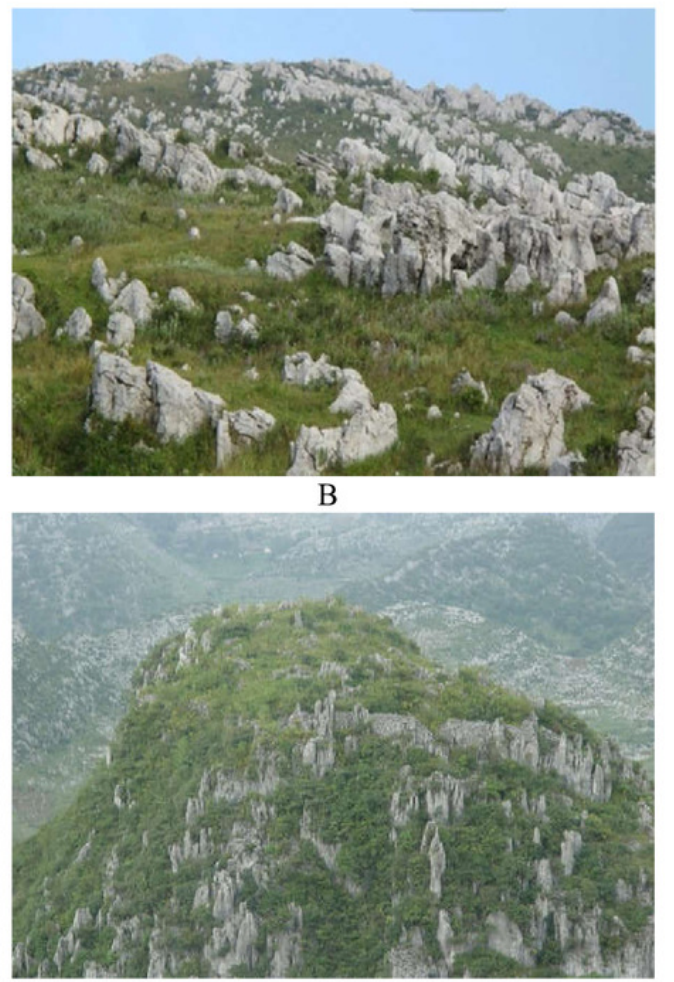

D

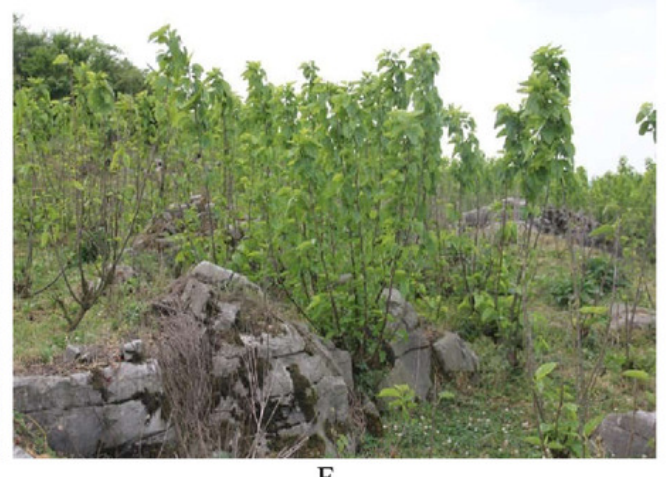

F

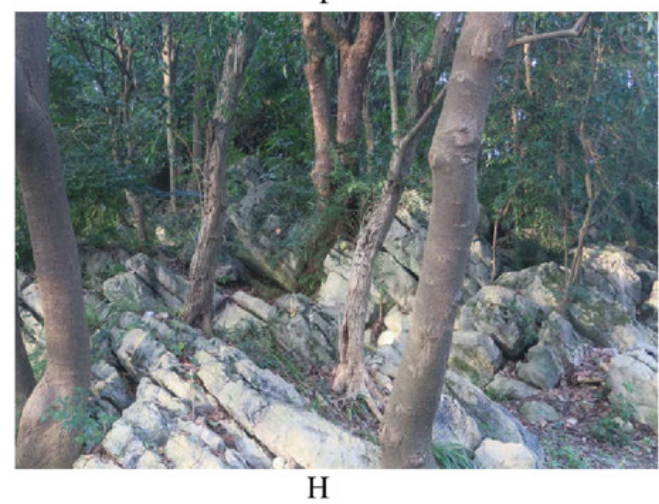




\section{Figure 2}

Changes in species richness in seed banks across different stages of secondary succession

$A, B$ and $C$ are the seed banks before field seed germination at the soil depths of $0-5,5-10$ and $10-15 \mathrm{~cm}$, respectively; D, E and $\mathrm{F}$ are the seed banks after field seed germination at the three different soil depths. Each stage of secondary succession corresponds to twenty species richness values obtained from twenty soil samples in one layer of soil ( $N=160$ in each small figure). Species richness shows a normal distribution based on P-P figures. The variance in species richness at different successional stages is homogeneous. *, *, and ** represent significance at confidence levels of $95 \%, 99 \%$ and $99.9 \%$, respectively. $X$ in equations represents succession stages. The notation is the same in the table and the figures below. 

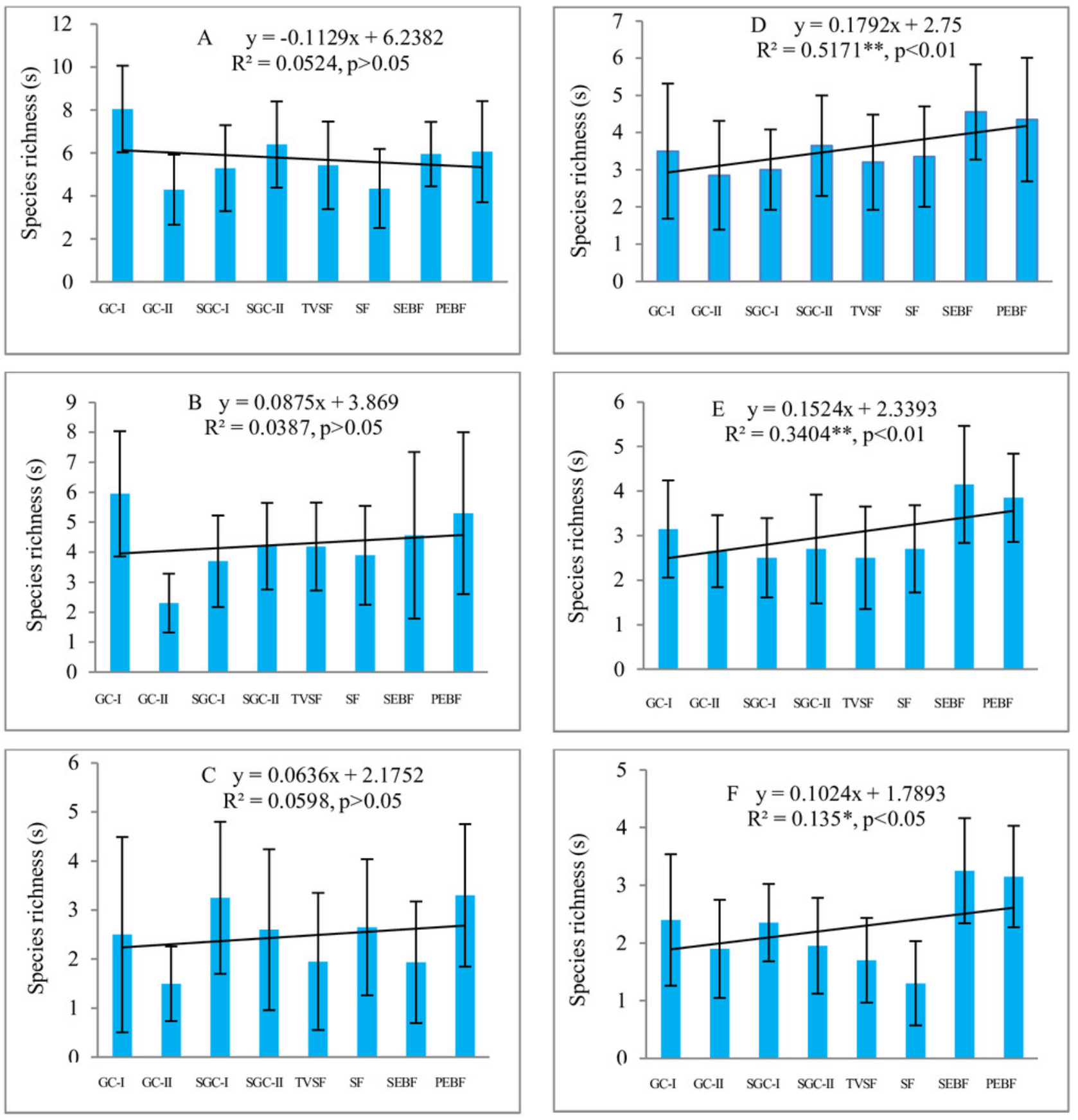


\section{Figure 3}

Species richness of five plant life forms in seed banks before field seed germination (A) and after field seed germination (B)

The species richness represented by each pillar is the number of all species of one life form recorded from 60 soil samples (total at three depths; each soil sample is collected from a 10 $\mathrm{cm} \times 10 \mathrm{~cm}$ plot) in one succession stage. The species richness of all plant life forms shows a normal distribution based on P-P figures. The variance of the species richness for ephemeral and perennial plants (excluding shrubs, vines and trees) in different successional stages is homogeneous. 

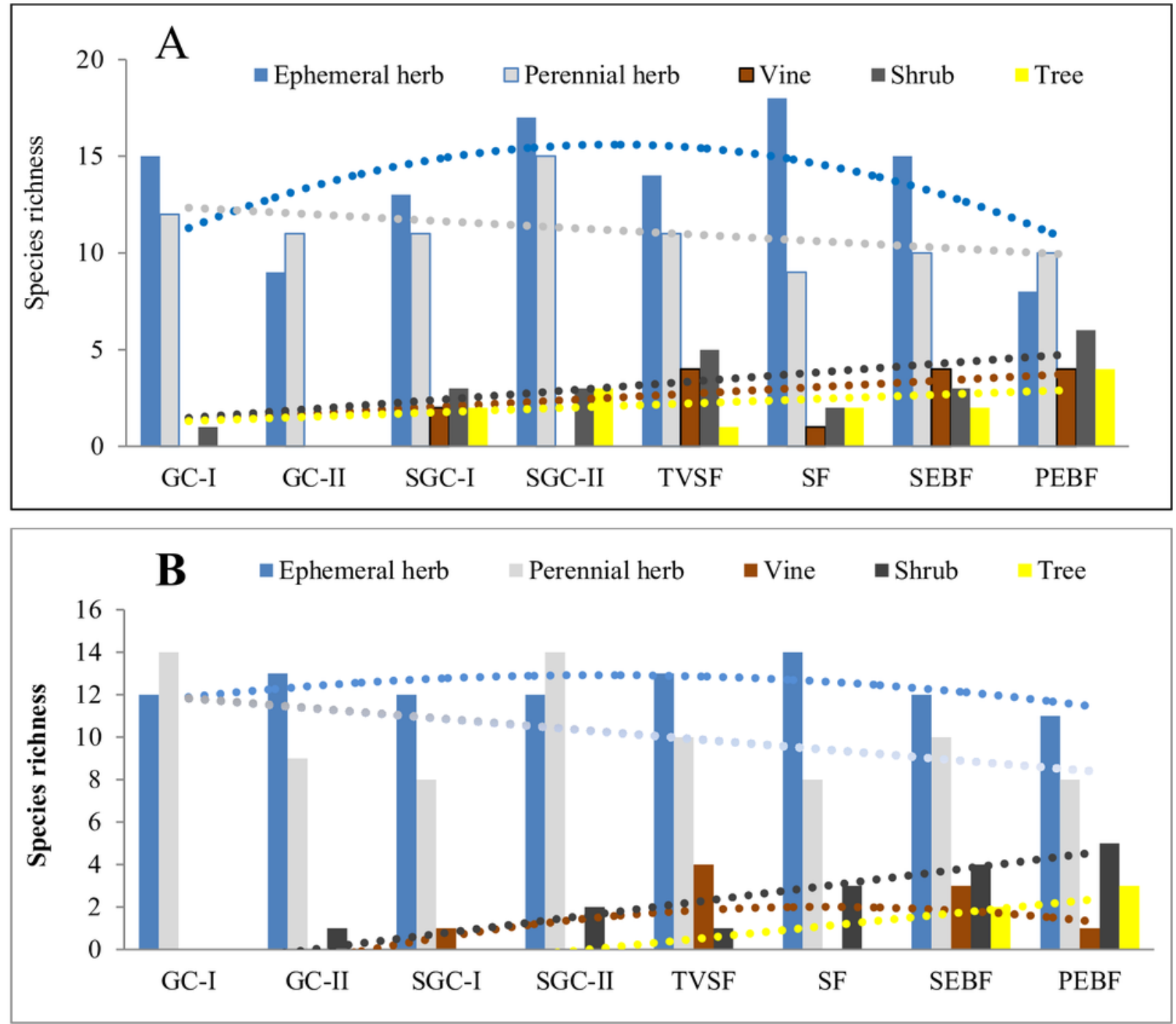


\section{Figure 4}

Relationship of the species richness in seed banks with the species richness of aboveground vegetation

$A, B$ and $C$ represent species richness in soil seed banks before field seed germination at depths of 0-5, 5-10 and 10-15 cm, respectively; D, E and F represent the soil seed banks after field seed germination at the three depths. The value of each dot in the figures is the mean species richness determined from twenty soil samples collected in each succession stage. The species richness on the $x$-axis corresponding to each dot in the figures is the mean species richness surveyed from four plots (for woody plants) and 12 subplots (for herb plants) in each succession stage. Note: the species richness of the aboveground vegetation and seed banks is highest in middle succession stages. Species richness shows a normal distribution based on P-P figures. The variance of species richness associated with different levels of the species richness of aboveground vegetation is homogeneous based on statistical tests. 

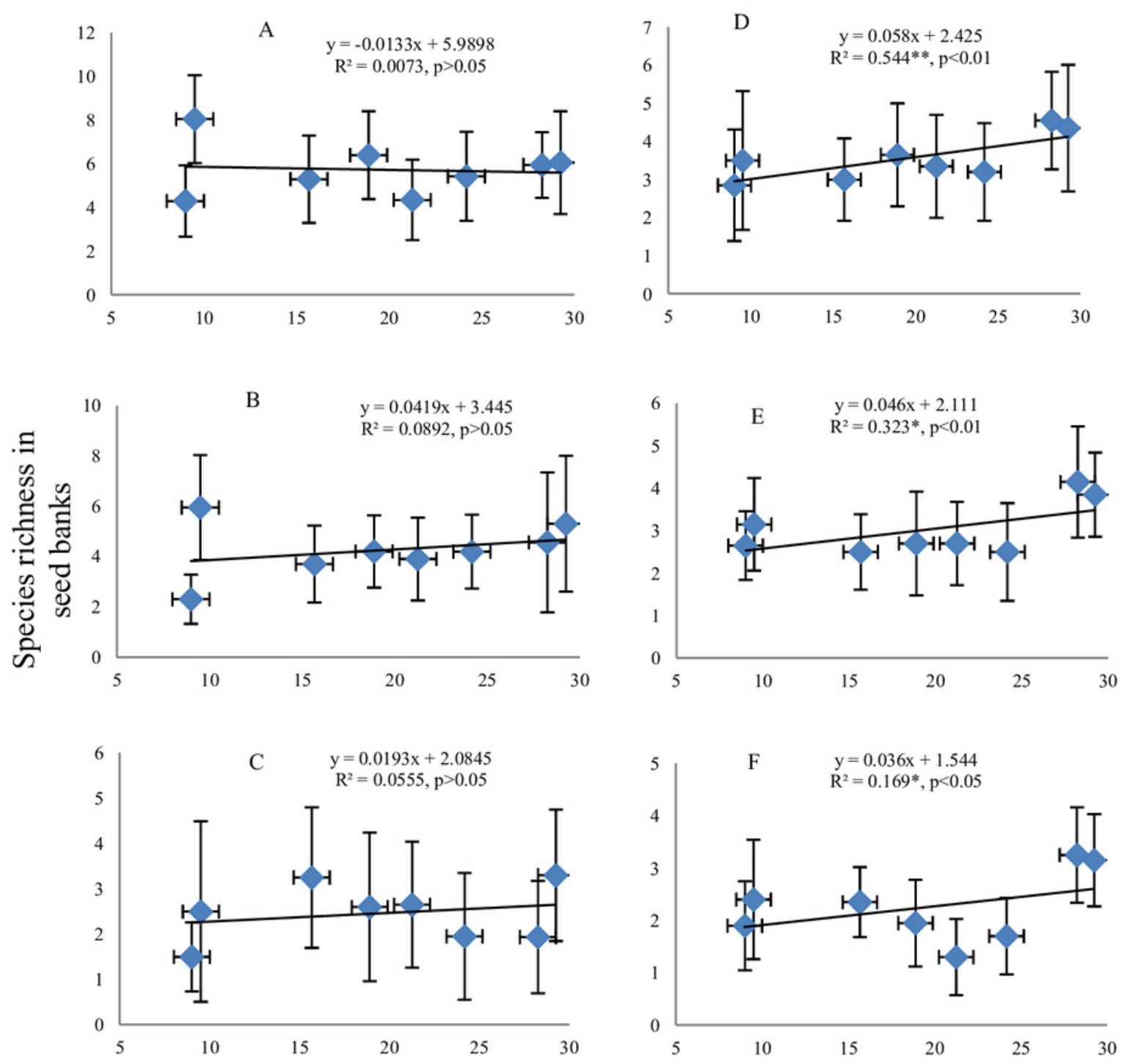

Species richness in vegetation 


\section{Figure 5}

Relationship of the species richness of different life forms in seed banks with the species richness of aboveground vegetation

$A, B, C, D$ and $E$ represent the ephemeral herbs, perennial herbs, vines, shrubs and trees, respectively, included in seed banks before field seed germination; F, G, H, I, and J represent the ephemeral herbs, perennial herbs, vines, shrubs and trees, respectively, included in seed banks after field seed germination. The values of each dot in the figures are the mean species richness tested from sixty soil samples (total at three soil depths) in each stage of secondary succession. Species richness on the $X$-axis is the same as in Fig. 4. The species richness of all plant life forms shows a normal distribution based on P-P figures. The variance of the species richness at different levels of the species richness of aboveground vegetation is homogeneous based on statistical tests. 


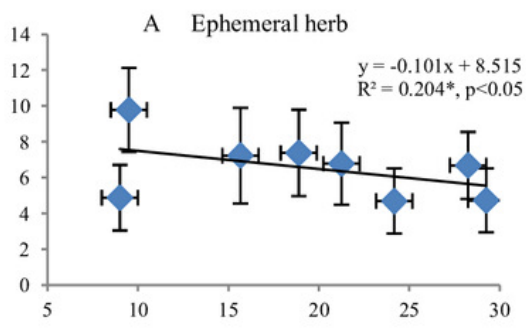

F Ephemeral herb
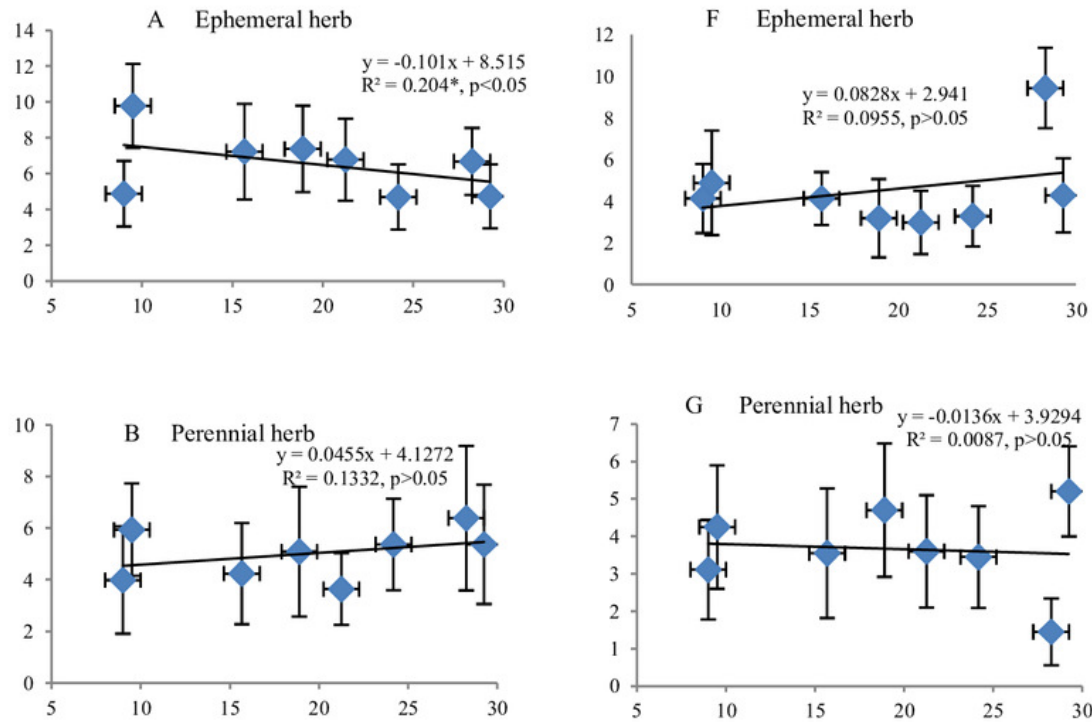

G Perennial herb $y=-0.0136 x+3.9294$
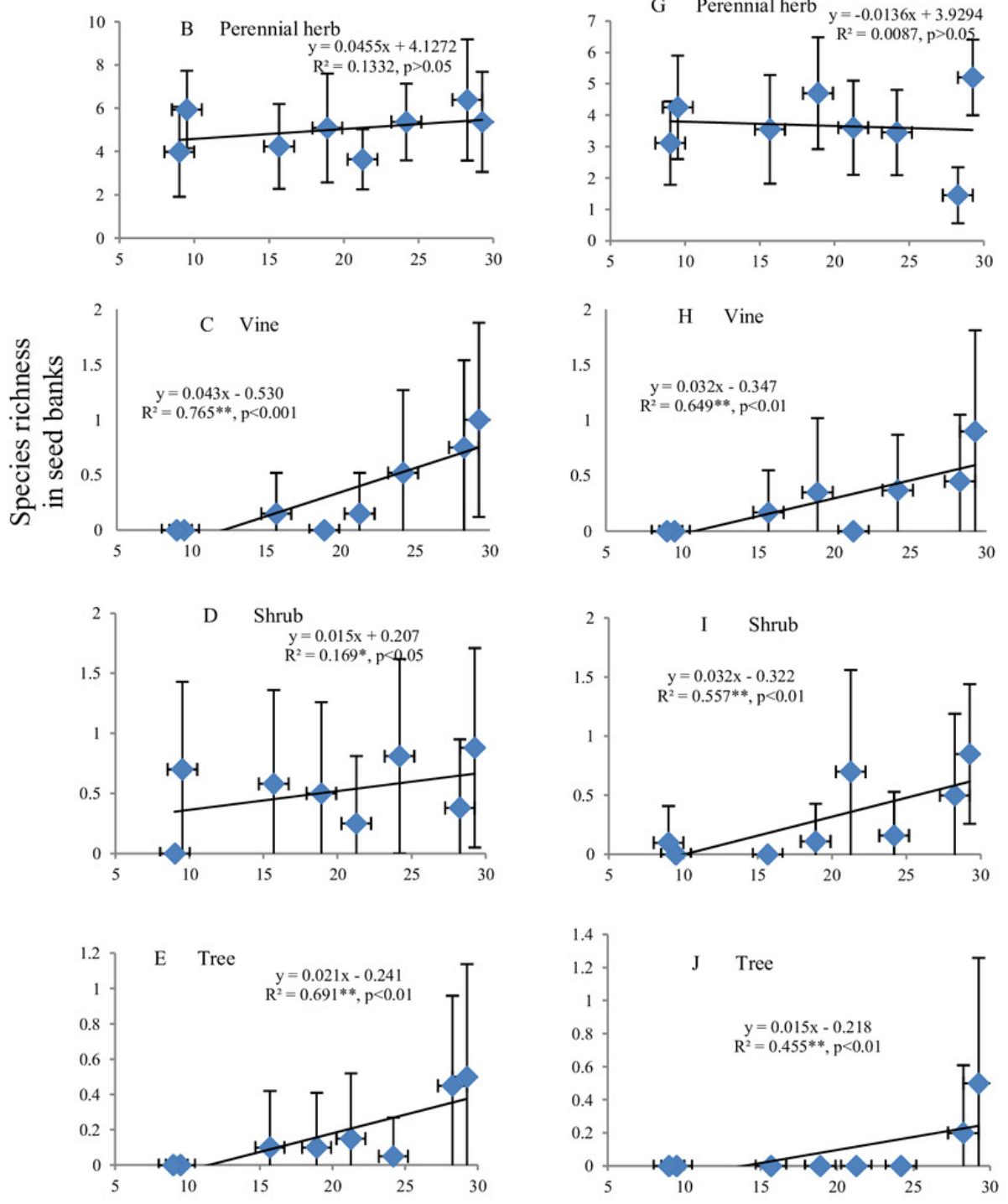

Species richness in vegetation 


\section{Table $\mathbf{1}$ (on next page)}

Number of recorded seedlings and species germinated from soil samples

Notes: GC-I: grass community-I; GC-I: grass community-II; SGC-I: shrub-grass community; SGC-II: shrub-grass community II; SF: shrub forests; SEBF: secondary evergreen broadleaf forest; TVSF: thorn-vine shrub forest; PEBF: primitive evergreen broadleaf forest. B: before field seed germination; A: after field seed germination. These abbreviations are the same in the tables and figures below. Max: the greatest number of seedlings among all recorded species; Min: the lowest number of seedlings among all recorded species; Average: the average for all recorded species; Total number of species: the total number of recorded species in seed banks both before and after field seed germination. Data for A or B in each succession stage were obtained from 60 soil samples at three depths, and each soil sample was collected from a $10 \mathrm{~cm} \times 10 \mathrm{~cm}$ plot. 
Table 1 Number of recorded seedlings and species germinated from soil samples

\begin{tabular}{|c|c|c|c|c|c|c|c|c|c|c|c|c|c|c|c|c|c|}
\hline \multirow{2}{*}{$\begin{array}{c}\text { Succession stages } \\
\text { Time of seed germination }\end{array}$} & \multicolumn{2}{|c|}{ GC-I } & \multicolumn{2}{|c|}{ GC-II } & \multicolumn{2}{|c|}{ SGC-I } & \multicolumn{2}{|c|}{ SGC-II } & \multicolumn{2}{|c|}{ TVSF } & \multicolumn{2}{|c|}{$\mathrm{SF}$} & \multicolumn{2}{|c|}{ SEBF } & \multicolumn{2}{|c|}{ PEBF } & \multirow[t]{2}{*}{$\begin{array}{c}\text { Tota } \\
1 \\
\end{array}$} \\
\hline & $\mathrm{B}$ & A & $\mathrm{B}$ & A & B & A & $\mathrm{B}$ & A & $\mathrm{B}$ & A & B & A & $\mathrm{B}$ & A & $\mathrm{B}$ & A & \\
\hline $\begin{array}{c}\text { Number of all recorded } \\
\text { seedlings }\end{array}$ & 491 & 302 & 751 & 328 & 621 & 292 & 685 & 306 & 590 & 225 & 504 & 259 & 868 & 469 & 528 & 480 & 7699 \\
\hline Max (seedling) & 83 & 50 & 101 & 35 & 65 & 33 & 80 & 43 & 101 & 43 & 61 & 33 & 106 & 72 & 100 & 81 & - \\
\hline Min (seedling) & 1 & 1 & 3 & 1 & 1 & 1 & 1 & 1 & 1 & 1 & 1 & 1 & 3 & 2 & 1 & 2 & - \\
\hline \multirow[t]{2}{*}{ Average (seedling) } & 24.5 & 13.1 & 26.8 & 12.6 & 20.7 & 10.8 & 18.0 & 10.9 & 18.4 & 9.0 & 14.4 & 9.2 & 25.5 & 15.1 & 16.0 & 17.1 & - \\
\hline & 5 & 3 & 2 & 2 & 0 & 1 & 3 & 3 & 4 & 0 & 0 & 5 & 3 & 3 & 0 & 4 & \\
\hline Number of species & 20 & 23 & 28 & 26 & 30 & 27 & 38 & 28 & 32 & 25 & 35 & 28 & 34 & 31 & 33 & 28 & - \\
\hline Number of common species & \multicolumn{2}{|c|}{11} & \multicolumn{2}{|c|}{14} & \multicolumn{2}{|c|}{15} & \multicolumn{2}{|c|}{16} & \multicolumn{2}{|c|}{17} & \multicolumn{2}{|c|}{18} & \multicolumn{2}{|c|}{19} & \multirow{2}{*}{\multicolumn{2}{|c|}{$\begin{array}{l}19 \\
42\end{array}$}} & - \\
\hline Total number of species & \multicolumn{2}{|c|}{32} & \multicolumn{2}{|c|}{40} & \multicolumn{2}{|c|}{42} & \multicolumn{2}{|c|}{50} & \multicolumn{2}{|c|}{40} & \multicolumn{2}{|c|}{45} & \multicolumn{2}{|c|}{46} & & & 89 \\
\hline
\end{tabular}

7 Notes: GC-I: grass community-I; GC-I: grass community-II; SGC-I: shrub-grass community; SGC-II: shrub-grass

8 community II; SF: shrub forests; SEBF: secondary evergreen broadleaf forest; TVSF: thorn-vine shrub forest; PEBF:

9 primitive evergreen broadleaf forest. B: before field seed germination; A: after field seed germination. These

10 abbreviations are the same in the tables and figures below.

11 Max: the greatest number of seedlings among all recorded species; Min: the lowest number of seedlings among all

12 recorded species; Average: the average for all recorded species; Total number of species: the total number of 13 recorded species in seed banks both before and after field seed germination.

14 Data for A or B in each succession stage were obtained from 60 soil samples at three depths, and each soil sample

15 was collected from a $10 \mathrm{~cm} \times 10 \mathrm{~cm}$ plot.

17 


\section{Table 2 (on next page)}

Total seed density in seed banks at three soil depths in different stages of secondary succession

Unit, seedlings $/ \mathrm{m}^{2}$; S. E., standard error; B, before field seed germination; A, after field seed germination. All data in the table show a normal distribution based on P-P figures. Both before and after field seed germination, the data on the seed density in the seed banks at each depth were obtained from 20 soil samples. 
Table 2 Total seed density in seed banks at three soil depths in different stages of secondary succession

\begin{tabular}{cccccc}
\hline Succession stages & $\begin{array}{c}\text { Time of field seed } \\
\text { germination }\end{array}$ & $\begin{array}{c}0-5 \mathrm{~cm} \text { depth } \\
(\text { Mean } \pm \text { S.E) }\end{array}$ & $\begin{array}{c}5-10 \mathrm{~cm} \text { depth } \\
(\text { Mean } \pm \text { S.E. })\end{array}$ & $\begin{array}{c}10-15 \mathrm{~cm} \text { depth } \\
\text { (Mean } \pm \text { S.E. })\end{array}$ & $\begin{array}{c}\text { Total } \\
\text { (Mean } \pm \text { S.E. })\end{array}$ \\
\hline \multirow{2}{*}{ GC-I } & B & $1445 \pm 778$ & $710 \pm 333$ & $300 \pm 212$ & $2455 \pm 951$ \\
& A & $670 \pm 217$ & $500 \pm 145$ & $340 \pm 153$ & $1510 \pm 400$ \\
GC-II & B & $1815 \pm 582$ & $1200 \pm 657$ & $740 \pm 785$ & $3755 \pm 1317$ \\
& A & $725 \pm 266$ & $510 \pm 141$ & $415 \pm 149$ & $1650 \pm 387$ \\
SGC-I & B & $1440 \pm 724$ & $1035 \pm 411$ & $630 \pm 263$ & $3105 \pm 975$ \\
& A & $600 \pm 217$ & $480 \pm 140$ & $380 \pm 87$ & $1460 \pm 309$ \\
SGC-II & B & $1745 \pm 784$ & $1030 \pm 233$ & $650 \pm 637$ & $3425 \pm 1014$ \\
& A & $705 \pm 213$ & $480 \pm 172$ & $345 \pm 163$ & $1530 \pm 456$ \\
TVSF & B & $1330 \pm 465$ & $980 \pm 262$ & $640 \pm 227$ & $2950 \pm 705$ \\
& A & $530 \pm 162$ & $380 \pm 133$ & $245 \pm 172$ & $1155 \pm 380$ \\
SF & B & $1229 \pm 195$ & $843 \pm 177$ & $460 \pm 159$ & $2531 \pm 382$ \\
& A & $590 \pm 241$ & $420 \pm 206$ & $285 \pm 182$ & $1295 \pm 436$ \\
SEBF & B & $989 \pm 289$ & $644 \pm 307$ & $289 \pm 240$ & $1922 \pm 461$ \\
& A & $440 \pm 123$ & $342 \pm 80$ & $260 \pm 63$ & $1042 \pm 178$ \\
PEBF & B & $731 \pm 409$ & $508 \pm 224$ & $228 \pm 210$ & $1467 \pm 678$ \\
& A & $467 \pm 110$ & $336 \pm 64$ & $284 \pm 71$ & $1078 \pm 164$ \\
\hline
\end{tabular}

7 Unit, seedlings $/ \mathrm{m}^{2}$; S. E., standard error; B, before field seed germination; A, after field seed germination. All data

8 in the table show a normal distribution based on P-P figures. Both before and after field seed germination, the data

9 on the seed density in the seed banks at each depth were obtained from 20 soil samples. 


\section{Table 3(on next page)}

Seed density of different life forms in seed banks in different succession stages

Unit, seedlings $/ \mathrm{m}^{2}$; B, before field seed germination; $\mathrm{A}$, after field seed germination. The statistics are based on the same sample number as in Table 2 . 
1

2

3

4

5

Table 3 Seed density of different life forms in seed banks in different succession stages

\begin{tabular}{|c|c|c|c|c|c|c|}
\hline Succession stages & Time of field seed germination & Ephemeral herb & Perennial herb & Vine & Shrub & Tree \\
\hline \multirow[t]{2}{*}{ GC I } & $\mathrm{B}$ & 2365 & 1250 & 0 & 140 & 0 \\
\hline & A & 810 & 830 & 0 & 0 & 0 \\
\hline \multirow[t]{2}{*}{ GC II } & $\mathrm{B}$ & 1665 & 1200 & 0 & 0 & 0 \\
\hline & A & 890 & 625 & 0 & 10 & 0 \\
\hline \multirow[t]{2}{*}{ SGC I } & $\mathrm{B}$ & 1940 & 1015 & 20 & 105 & 20 \\
\hline & A & 760 & 665 & 35 & 0 & 0 \\
\hline \multirow[t]{2}{*}{ SGC II } & $\mathrm{B}$ & 1975 & 1320 & 0 & 115 & 15 \\
\hline & A & 575 & 860 & 75 & 20 & 0 \\
\hline \multirow[t]{2}{*}{ TVSF } & $\mathrm{B}$ & 1845 & 1015 & 15 & 55 & 20 \\
\hline & A & 445 & 600 & 0 & 110 & 0 \\
\hline \multirow[t]{2}{*}{ SF } & $\mathrm{B}$ & 1135 & 1085 & 90 & 135 & 0 \\
\hline & A & 615 & 605 & 50 & 25 & 0 \\
\hline \multirow[t]{2}{*}{ SEBF } & $\mathrm{B}$ & 796 & 968 & 86 & 29 & 31 \\
\hline & A & 812 & 121 & 48 & 40 & 11 \\
\hline \multirow[t]{2}{*}{ PEBF } & $\mathrm{B}$ & 486 & 513 & 86 & 51 & 26 \\
\hline & A & 409 & 504 & 33 & 84 & 33 \\
\hline
\end{tabular}

6 Unit, seedlings $/ \mathrm{m}^{2}$; B, before field seed germination; A, after field seed germination. The statistics are based on the

7 same sample number as in Table 2.

8 


\section{Table 4 (on next page)}

Similarity of plant species between the seed bank and aboveground vegetation

$C_{j}$, Jaccard index; B and A represent seed banks before and after field seed germination, respectively. The calculation of $C_{j}-B$ or $C_{j}-A$ at a $0-15 \mathrm{~cm}$ soil depth for each stage is based on the plant species identified from 60 soil samples and the data of aboveground vegetation (Supplementary Information I). The calculation of $C_{j}-B$ or $C_{j}-A$ at each of the other three soil depths is based on the plant species identified from 20 soil samples and the data of aboveground vegetation. 
Table 4 Similarity of plant species between the seed bank and aboveground vegetation

\begin{tabular}{|c|c|c|c|c|c|c|c|c|c|}
\hline \multirow{2}{*}{ Jaccard index } & \multirow{2}{*}{ Soil depths } & \multicolumn{5}{|c|}{ SGC- } & \multirow[b]{2}{*}{ SF } & \multirow[b]{2}{*}{ SEBF } & \multirow[b]{2}{*}{ PEBF } \\
\hline & & GC-I & GC- II & I & SGC- II & TVSF & & & \\
\hline$C_{\mathrm{j}}-\mathrm{B}$ & $0-15 \mathrm{~cm}$ & 56.00 & 37.50 & 23.10 & 17.86 & 18.99 & 15.48 & 17.86 & 11.10 \\
\hline$C_{\mathrm{i}}-\mathrm{A}$ & $0-15 \mathrm{~cm}$ & 35.48 & 38.46 & 13.11 & 18.57 & 16.00 & 13.89 & 15.66 & 12.82 \\
\hline$C_{\mathrm{j}}-\mathrm{B}$ & $0-5 \mathrm{~cm}$ & 28.13 & 25.71 & 14.04 & 20.00 & 17.11 & 20.83 & 13.58 & 11.69 \\
\hline$C_{\mathrm{j}}-\mathrm{B}$ & $5-10 \mathrm{~cm}$ & 28.57 & 30.00 & 10.91 & 14.71 & 19.44 & 15.49 & 10.67 & 9.59 \\
\hline$C_{\mathrm{j}}-\mathrm{B}$ & $10-15 \mathrm{~cm}$ & 31.82 & 15.15 & 11.54 & 20.34 & 10.61 & 8.70 & 5.26 & 9.23 \\
\hline$C_{\mathrm{j}}-\mathrm{A}$ & $0-5 \mathrm{~cm}$ & 27.59 & 24.32 & 17.65 & 14.93 & 18.31 & 12.50 & 10.26 & 10.96 \\
\hline$C_{\mathrm{j}}-\mathrm{A}$ & $5-10 \mathrm{~cm}$ & 29.63 & 25.00 & 9.62 & 14.92 & 11.11 & 11.43 & 6.49 & 7.04 \\
\hline$C_{\mathrm{j}}-\mathrm{A}$ & $10-15 \mathrm{~cm}$ & 37.50 & 18.75 & 8.00 & 11.67 & 13.43 & 7.69 & 8.22 & 7.25 \\
\hline
\end{tabular}

$5 C_{\mathrm{j}}$, Jaccard index; $\mathrm{B}$ and $\mathrm{A}$ represent seed banks before and after field seed germination, respectively. The 6 calculation of $C_{j}$-B or $C_{\mathrm{j}}$-A at a $0-15 \mathrm{~cm}$ soil depth for each stage is based on the plant species identified from 60 soil 7 samples and the data of aboveground vegetation (Supplementary Information I). The calculation of $C_{j}$-B or $C_{\mathrm{j}}$-A at 8 each of the other three soil depths is based on the plant species identified from 20 soil samples and the data of 9 aboveground vegetation.

10 


\section{Table 5 (on next page)}

Fitted models of species richness of different life forms in different stages of secondary succession

Independent variables (i.e., succession stages) were automatically assigned by the software (graded values of 1-8 for regression analysis). The data for the dependent and independent variables show a normal distribution based on P-P figures. In the fitted models for vines, shrubs and trees, random factors have a statistically significant influence on the dependent variables in addition to the independent variables based on statistical tests. The number of samples is the same as in Fig. 3. 
1

2

3

4

\begin{tabular}{|c|c|c|c|c|}
\hline Time of field seed germination & Life forms & Models & $R^{2}$ & $p$ \\
\hline \multirow[t]{5}{*}{ Before field seed germination } & Ephemeral herb & $Y=-0.375 \times 2+3.291 x+8.375$ & $0.272 *$ & $<0.05$ \\
\hline & Perennial herb & $Y=-0.089 \times 2+0.458 x+11.33$ & $0.277 *$ & $<0.05$ \\
\hline & Vine & $Y=0.337 x+1.040$ & $0.211^{*}$ & $<0.05$ \\
\hline & Shrub & $Y=0.467 x+1.016$ & $0.436 * *$ & $<0.01$ \\
\hline & Tree & $Y=0.228 x+1.076$ & $0.171^{*}$ & $<0.05$ \\
\hline \multirow[t]{5}{*}{ After field seed germination } & Ephemeral herb & $Y=-0.101 \times 2+0.851 x+11.12$ & $0.318^{*}$ & $<0.05$ \\
\hline & Perennial herb & $Y=-0.448 x+12.32$ & $0.223^{*}$ & $<0.05$ \\
\hline & Vine & $Y=-0.160 \times 2+1.910 x-3.678$ & 0.097 & $>0.05$ \\
\hline & Shrub & $Y=0.75 x-1.464$ & $0.810 * * *$ & $<0.001$ \\
\hline & Tree & $Y=0.6 x-2.466$ & $0.713 * *$ & $<0.01$ \\
\hline
\end{tabular}

Independent variables (i.e., succession stages) were automatically assigned by the software (graded values of 1-8 for regression analysis). The data for the dependent and independent variables show a normal distribution based on P-P figures. In the fitted models for vines, shrubs and trees, random factors have a statistically significant influence on 8 the dependent variables in addition to the independent variables based on statistical tests. The number of samples is the same as in Fig. 3. 